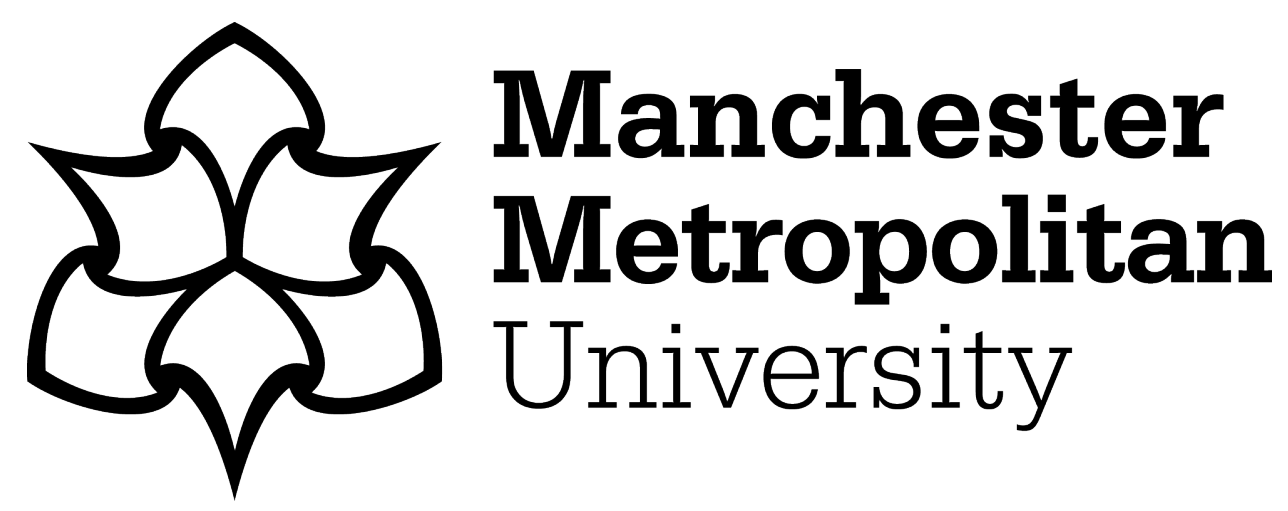

Tyler, D (2008) Advances in apparel product development. In: Advances in Apparel Production. Woodhead Publishing/Elsevier, pp. 157-177. ISBN 9781845692957

Downloaded from: https://e-space.mmu.ac.uk/622055/

Publisher: Woodhead Publishing/Elsevier

DOI: https://doi.org/10.1533/9781845694463.2.157

Please cite the published version 
Advances in apparel product development

D. T Y L E R, Manchester Metropolitan University, UK

\subsection{Introduction}

This chapter is concerned with new product development (NPD). There are numerous commercial pressures on companies involved in the supply of garments to consumers and they all come to a focus when considering the processes that link design with manufacturing and distribution. Globalisation has brought immense change to every aspect of the industry and this is the context for all the issues discussed here. The traditional process of NPD is described, together with indicators of the need for change. The major models of NPD are reviewed, identifying the concurrent product development approach as one that offers significant improvements. Tools and technologies relevant to the process are discussed, notably computer-aided design (CAD) development systems and product data management (PDM) software. The chapter goes on to consider the implementation of change, and shows that the role of the retailer (as supply chain leader) is crucial. Finally, discussion of fast fashion brings to a head the importance of restructuring the product development process to bring integration to internal systems and to supply chain management.

\subsection{Industrial change}

The past 25 years has seen a transformation in the way the clothing industry operates. In 1980, it was possible for all parties involved in the supply chain to attend meetings and to visit domestic spinning, weaving, knitting, dyeing/ finishing and clothing assembly plants. Suppliers of commodities (buttons, zips, threads, etc.) were also close to hand. If there were problems, telephone conversations could be followed by site visits in order to resolve them. Numerous technology specialists could be called on to become personally involved, whether the expertise required was in fabric production, wet processing or garment assembly. By contrast, the industry is now globalised, with textile production, garment manufacture and commodity supply scattered 
in different countries, separated by language, culture, geography and time zones. Problem resolution is frequently done remotely because there are too many constraints preventing people from physically meeting.

The industry has responded by investing in technologies supporting communication. E-mail is routine, as is also the use of spreadsheets and CAD systems. Some suppliers have gone further and are equipped with PDM systems and other more sophisticated software tools. Video-conferencing is increasingly available and Intranet-based approaches to data handling have been adopted.

However, the biggest challenges are organisational in nature. Supply chains are made up of companies and people, and technologies are, at best, tools in the hands of users. It is not just the challenge of supplying goods to the specified quality, but of building in responsiveness and reducing lead times. This is because retail markets are characterised by volatility. Traditional approaches to forecasting consumer demand have become increasingly inaccurate with consequences of excessive cost. Reducing lead times, from placing orders to the stores receiving goods, is a major strategy for reducing risk. All supply chains are being asked to enhance responsiveness by looking critically at lead times and finding ways to speed up the delivery of goods.

Undoubtedly, many of the technologies mentioned above have the ability to shorten lead times. CAD systems, for example, allow digitised pattern information to be e-mailed across the globe so that the supplier can grade the patterns and make markers to control cutting. Software ranging from spreadsheets to PDM systems handle a range of product information, including size chart data, quality requirements, care label instructions and the like. Proper use of these technologies ensures that the right information is present when and where it is needed, so lead times can be minimised.

It is unfortunate that many supply chain companies rarely get beyond these technological changes. This is not a reflection on their competence, but more a reflection on the supply chain as a whole. Organisational change that will deliver enhanced responsiveness needs wider participation and initiatives taken by companies acting alone will be perceived as ineffective because the measurable benefits are low. This chapter is concerned with organisational change affecting NPD, which is suggested to be the next critical area for achieving greater responsiveness in the supply of clothing products.

\subsection{Process model for clothing product development}

From a retail management perspective, the initiation of activity is the range plan. From a design and product development perspective, activity emerges as part of the cycle of 'design influences' (Fig. 8.1). The cycle includes: 


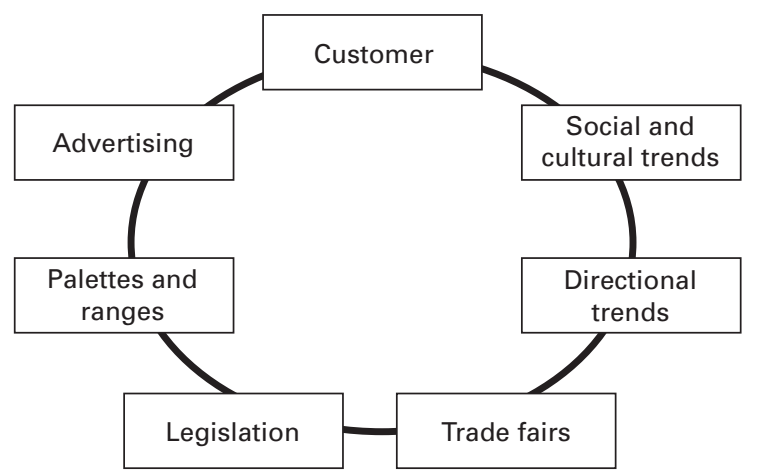

8.1 The design influences cycle.

- analysis of social and cultural trends;

- utilisation of design trend information;

- visits to fabric fairs, fashion shows, etc. to stimulate ideas;

- attention to any legislative constraints;

- preparation of ranges for selection by retail buyers/selectors;

- product and range development over several months, with several sealed samples followed by bulk production (often commencing weeks before goods are due in the shops);

- advertising and marketing of the products, seeking to influence demand.

The design work leading up to the development of palettes and ranges, and the product development work culminating in approved (sealed) samples for bulk production is illustrated in Fig. 8.2.

Many large retailers build their product ranges around two seasons: spring/ summer and autumn/winter. It is doubtful that any would insist that this approach is ideal. All seek to refresh their ranges within season. This is generally handled by the practice of 'phasing', whereby new products and ranges are introduced over shorter timescales. However, many of the decisions regarding the products to be phased in during the selling season are identified at the outset.

It appears, therefore, that the seasonality of the retailing product development timetable is still very strong and that major decisions regarding products and ranges continue to be decided very early on, before there is any demand-pull from consumers. As a consequence, the whole supply chain operates within this long product development cycle. For many years, trade fairs such as Premiere Vision have been perceived as triggers for initiating garment design activity (Forza and Vinelli, 1996). It is at this point of the design cycle that fabrics and colour palettes come into focus, although King (2007) reports that at least two major UK retail chains are making most of their colour management decisions before the shows. While companies vary in the details 


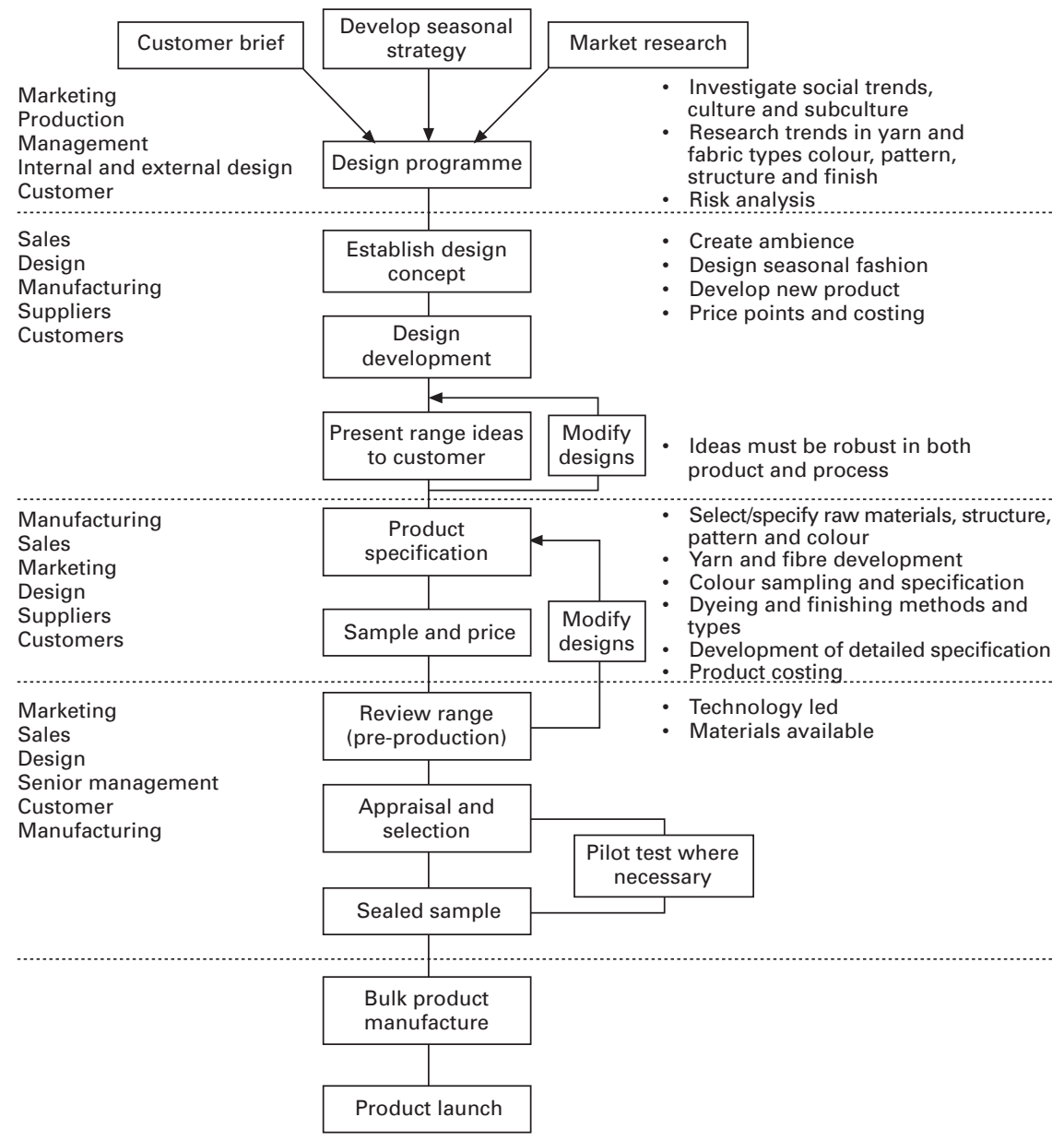

8.2 Process model, representative of many clothing products.

of their product development calendar, the majority are making decisions about their products well in advance of offering them for sale.

It has been suggested that the textiles and clothing sector has become locked into these long timescales and that this is against its long-term interests (Tyler et al., 2006). Calendars very easily become rigid because of trade events, and participants in the supply chain consider it advantageous to synchronise their activities with these events to maximise their own sales. The effect of this is to change the agenda for responsiveness in the supply chain: instead of time compression throughout product development, the overall timescale is fixed and decision points within the seasonal cycle are shifted towards the point of sale. This gives the impression that the main burden of enhancing responsiveness falls on suppliers. This is a misreading of the situation, and is discussed later in this chapter. 
An apparel supply chain benchmarking study (Anon., 1996/97) highlighted product development lead times as a weakness in the UK's international competitive position: 'One area we have highlighted is product availability - both from supplier to retailer and from retailer to consumer. While compared with overseas competitors UK manufacturers' production lead times were the shortest, this was counterbalanced by the fact that developing the product in the first place is not as effective as international competition.' This benchmarking study of the UK textiles and clothing sector revealed that product development was a major area for improvement. The findings showed that timescales are long, there is much wasted effort, and that communications between the different functions - design, production, marketing, sales - are poor. Watson (1997), who managed the study, estimated that, on average, only $30 \%$ of the products developed actually found their way into the store (with designs often being adapted or modified more than four times from first sample to final approval), revealing further some of the inefficiencies of the product development process, possibly as a result of these communication problems. Watson provided this statistical summary: 'the product development cycle in the UK currently takes on average 167 days, the manufacturing part of this is only 39 days, so the industry spends a lot of time deciding what to manufacture, and clearly, this is both a direct and indirect cost.' These figures are not so dissimilar to those obtained by other industries, where the manufacturing lead time is comparatively short in relation to the product development time. Product developers need to reflect on their own processes and consider whether their timescales are justified and whether they can themselves contribute to time compression. It should be pointed out that all personnel involved with NPD are very busy and have many deadlines to meet, so any thought of shortening the timescales is regarded as unrealistic. However, the point being made here is about process: it is not how hard people are working but what activities make up their working lives.

\subsection{Models of new product development}

There are three themes that consistently appear in literature related to product development success factors. These are summarised by Hart and Baker (1994).

1. Interdisciplinary inputs. It has always been recognised that different disciplines are needed in the process of NPD. Successes are typically linked with professionals from different disciplines actively collaborating.

2. Good quality information inputs. Whether it involves technical inputs from suppliers, or consumer-related information from marketing, all information sources must be accurate and timely. 
3. Short lead times. The ability to launch market-relevant products quickly can be translated into financial benefits. Nevertheless, there are also risks, and organisations wishing to beat their competitors on 'time-tomarket' must manage the process carefully.

Consequently, NPD analysts have been stimulated to scrutinise models and procedures for how they handle these issues and how improvements can be made. A useful starting point for thinking about process is to consider different models of the NPD process, as identified by Saren (1984) and discussed by Hart and Baker (1994). Saren has five models in all, but the first three are particularly relevant to our interests here.

1. Departmental-stage models. This is the classic 'functional independence' approach, where each department or function has clearly identified objectives, and the 'product' is signed-off as it moves from one stage to the next. While appearing to be logically sound, it suffers from the presumption that product objectives can be achieved by a reductionist approach (i.e. the sum of the distinct objectives of each function).

2. Activity-stage models. The approach is product-focused (rather than influenced by functional boundaries) and the activities needed to develop the product are identified at an early stage. Resources are then made available to support those activities and achieve the desired outcome. Although an improvement over model 1, the approach has been criticised for continuing the 'pass the parcel' tradition because activities are still closely linked to functions within organisations. In many cases, including clothing product development, the distinction between models 1 and 2 is hard to discern.

3. Decision-stage models. The NPD process is represented as a series of staging points, where progress is evaluated and where decisions are made to continue or abandon the project. Activities in each stage are selected so that the point can be reached where a meaningful decision can be made at the end of that stage. A possible problem with this model is that the emphasis appears to be on the decision points, but what goes on in the intervals between decision points is just as important as having staged evaluations. Nevertheless, this model does provide an opportunity to break out of the departmental/functional framework and to develop team-based approaches to product development.

These models allow a broad comparison to be made between sequential approaches to NPD (represented by models 1 and 2) and concurrent approaches (represented by model 3). Comparisons and contrasts have frequently been made in other industrial sectors. Numerous industries in many countries have faced similar challenges to improve NPD processes. Sequential processes are deficient because product development decisions cannot be made without 
reference to the end-product. Functional and activity boundaries are walls that inhibit vision. Decisions are often made that are non-optimal for subsequent functions or activities and they have to be re-made. For example, a specific design feature may be achieved by a particular assembly technique that can be completed satisfactorily by a sample machinist, but in manufacture, the assembly technique may not be commercial because it is too slow, or because it leads to excessive problems of quality failure. The assembly technique needs to be appraised by garment technologists and manufacturing specialists and their work needs to inform the design process.

This sequential approach is often described as each department 'tossing the product over the wall' to the next in line, with communication being portrayed as linear (as in Fig. 8.3). The approach has an embedded problem: the adoption of functional independence. This is because getting the product right for the market actually requires functional interdependence. Laterstage functions either do the best they can with the product as they have received it (which means that compromises are inevitable) or they return the product to the relevant function with a request for further design/development work (which means time delays and additional costs).

By contrast, the concurrent product development process can be likened to a relay race where a baton (the product) is carried by a succession of runners from the start (design concept) to the finish (in the hands of a satisfied consumer) in the shortest possible time. Transfer of the baton from one runner to the next must be handled well so there are no errors and delays. Relay runners must each make their distinctive contribution, but the transfer of the baton is critical to success, and this requires common goals, coordination, communication and concurrent activity.

The need for better quality and shorter product development lead times is widely acknowledged. There has been a growing realisation that the concurrent product development approach (model 3) offers an effective way to achieve these objectives and it is a recognised strategy for enhancing competitiveness and for overcoming the problems emerging from sequential routes for NPD (Bhamra et al., 1998). Figure 8.2 has, on the left-hand side, a listing of possible team members for each stage of the process. There are

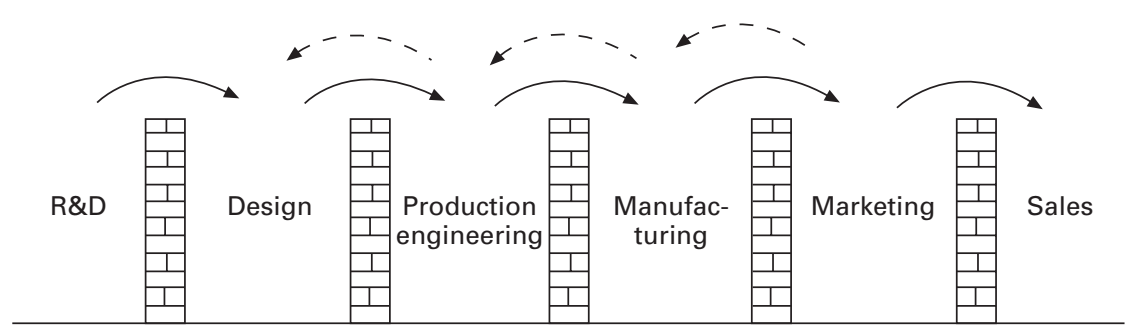

8.3 The sequential approach to NPD and the problems of reworking decisions made at earlier stages. 
different functions represented who become involved when they have a contribution to make. The team's role is to take the products through each stage in turn, ensuring that, after the decision points, the project can be handed on smoothly.

Figure 8.4 provides an overview of how product development might operate using the principle of concurrency (Tyler, 2008). The starting point is a proposal for a new product (and associated manufacturing processes) from a new products team. This feeds into a global design optimisation procedure.

- Stage 1 is Optimisation of manufacture. Product and process plans are scrutinised carefully to achieve integration, and the output is a product design plan.

- Stage 2 is Simplification, where the product design plan is analysed in terms of its target customers and over-designed features are removed. At this stage, there may be simplification to achieve a retail customer's price point.

- Stage 3 is Materials optimisation. This looks at the design plan in terms of materials selection, tolerances, performance in use and so on. Alternative materials are considered and evaluated on performance and cost.

- Stage 4 is the Environmental analysis. The product design plan is considered in the light of the environmental policies of both company and customer. Abridged life-cycle analyses are carried out to address

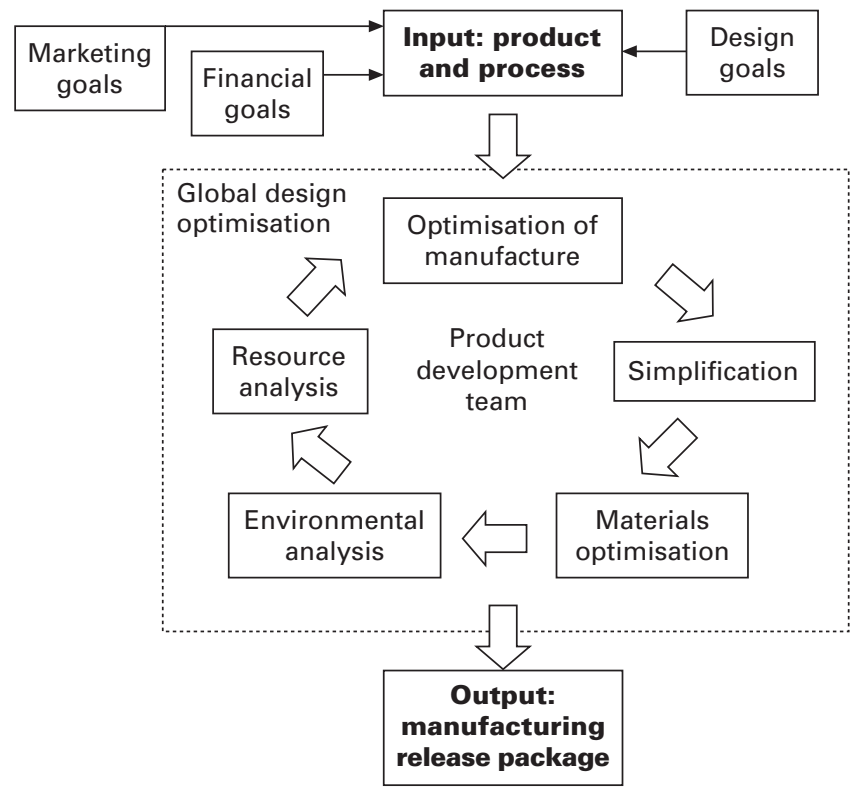

8.4 Overview of the concurrent product development approach. 
issues of waste in manufacture and in the supply chain. Alternative technologies are explored to improve the environmental profile of the product.

- Stage 5 is the Resource analysis. This looks at the resources required and available, and produces a resource-dependent design plan.

The global design optimisation loop is entered again at Stage 1 and continues until a satisfactory outcome is reached.

Technologists have a vital role to play in every stage of this product development model. Sometimes, the main channels of communication are with production people (as in the optimisation of manufacture and resource analysis); at other times, the focus is on the design aspects of the product (as in simplification and materials optimisation). The environmental analysis promotes communication throughout the supply chain and, here also, there are opportunities for technologists to contribute.

The major challenge with this approach is that companies are not used to a structured, managed process and there are often numerous pressures to make decisions pragmatically. Furthermore, people are not used to working in multi-disciplinary project teams, especially if they involve different companies in the supply chain.

\subsection{Product development tools and application areas}

The global context for clothing supply has already been identified above, with the corresponding problem of reduced opportunity for co-located meetings. Tools for NPD are required not only for completing specific tasks, but also for supporting international communication. This is not such an issue with a sequential process, but it is very important where companies have adopted concurrent product development. Transparency of information is a desirable goal and appropriate tools will deliver it. As Gereffi (1999) points out, industrial upgrading is a continuous process that is moving centres of expertise away from sourcing countries towards suppliers. In many cases, the retail customer or brand owner has outsourced all technical work with patterns, retaining only the creative design function. In some cases, even design has moved offshore. In such a fluid situation, efficient and effective NPD communication must be a priority.

CAD software for pattern specification, grading and marker making has long been used in the industry, and it is difficult to regard these as other than indispensable. Digital information can be communicated easily and in ways that are compatible with globalised supply chains. Other software tools are used at the design stage, for forecasting, designing and collection planning. These are outlined in Cooklin (2006) but are mostly stand-alone tools that do 
not communicate outside the design office. Research seeking to integrate $\mathrm{CAD}$ technologies and to extend downstream to the manufacturing process is discussed by Istook (2000).

PDM systems are rather different: they are designed to ensure the accessibility of up-to-date information. Pre-globalisation, the need for data communication was often met by the use of customised spreadsheets. Companies would design pages for the different types of data and the format was simple to pass around. The problems come as the systems grow and as the volume of data expands. The number of sheets can get very large, and different customers may need to have different customised formats of spreadsheet, so the task of maintaining and updating the database becomes overwhelming. Companies struggle with several extant versions of the database and old information is not quickly removed from the system. Information flows in clothing supply chains do not have a good track record of working well (Popp, 2000). In summary, product development information is difficult to manage for the following reasons:

- information overload;

- incompatible formats (e.g. computer disks, paper documents, etc.);

- users in different functions have varying needs and skill levels;

- difficulties in updating all users quickly to the current version;

- different terms are used to define the same data.

PDM suppliers have identified the practical problems of traditional procedures as follows:

- limited standardisation;

- errors and duplication;

- lack of workflow tracking;

- inefficient processes;

- ineffective processes.

This is where PDM, particularly its web-based versions, offers to satisfy a real need. The aims of PDM are as described below.

- To control product data (standardised formats, up-to-date information, data security, movement of information).

- To integrate data across functions (avoidance of duplication, easy access to data entered by other functions, transparency).

- To ensure one extant version (all data held centrally, changes and updates made to master only, up-to-date information communicated to all terminals).

- To support process management (enhanced communication, documented product history including times for completing development stages).

- To reduce lead times (reduction of time spent administering the process, reduced errors and more 'right-first-time' activity, reduced delays waiting for information). 
The basic structure of a PDM system is to have a folder containing all the information relevant to any particular style. Some of this information will be links to standard data sets - such as size specifications, colour standards, quality standards, instructions on how to take measurements, finishing procedures and packaging procedures. The folder will have the ability to store images, to develop a costing for the product, to record all communications about that product and to document progress in product development and in manufacture. Instead of starting each new style with an empty folder, data entry can be minimised by copying a past similar style and editing the data that need alteration. This architecture makes PDM an ideal tool for use with the concurrent product development approach (Gascoigne, 1995).

As with all software systems, PDM software is continually being updated to give enhanced performance. Such facilities may include integrated e-mail, language translation for use in different countries, the ability to store video clips, libraries to support labelling and the incorporation of standard procedures for cutting, sewing, pressing, inspection and packaging. Users may have the option of customising their own forms for data viewing and reporting. Quality data and other test results can be entered to the database with exception reporting to management.

Concurrent product development approaches come with their own suite of tools. The most important relate to the decision gates (Fig. 8.5), following development activity to achieve agreed objectives. Another important tool is the product development cost model (enabling informed selection of projects using product cost/quality/development speed/development cost trade-offs). Numerous other formal methods have been developed, several of which are not feasible at all with sequential approaches to NPD. These include Design for Manufacture (DFM), Quality Function Deployment (QFD) and Design for Environment (DfE). DFM is a structured approach to ensure the product can be released to be manufactured without experiencing the costly technical and quality problems that occur during start-up. QFD is a structured approach to identifying the voice of the consumer and translating user needs into technical requirements. DfE brings an environmental emphasis to NPD based on designing good practice into the product rather than leaving it to the manufacturers to improve the environmental impact by cleaning up the manufacturing processes (so-called 'end-of-pipe' solutions). For more on DfE for clothing products, see Bhamra et al. (1998).

\subsection{Product lifetime management (PLM)}

The trend in information technology (IT) systems is towards integration of software modules. In particular, PDM software has the potential to be part of an even larger system that draws together all aspects of the activities of a company. Figure 8.6 illustrates the main modules: 


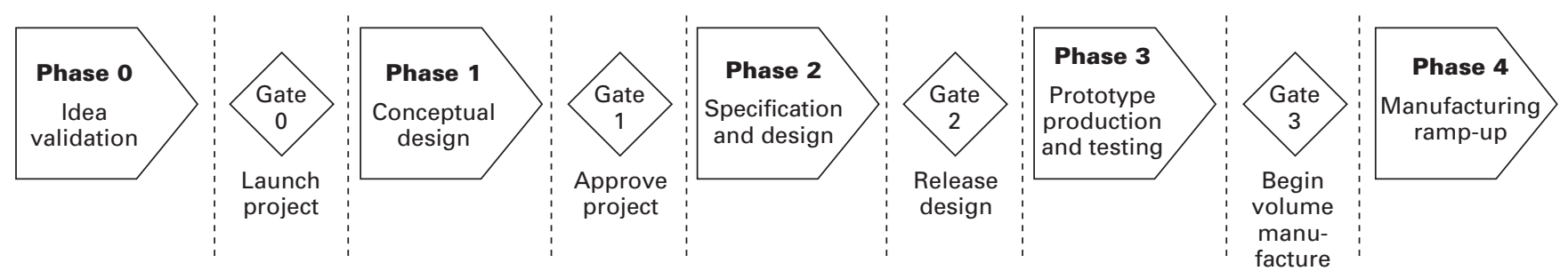

8.5 The gate review tool. This provides for a structured review process taking place at various key stages in the project. The gates represent a go/no-go decision to proceed to the next phase. 
- PDM (Product Data Management) for managing all data relating to product development and specification;

- PPM (Production Planning and Management) for production planning and management;

- ERP (Enterprise Resource Planning) for resource planning throughout the enterprise;

- CRM (Customer Relationship Management) for managing all links with customers.

All these modules can, in principle, read from and write to a common database. The vision is for an information system that does not create walls within the business that block information flows. Figure 8.6 shows a closed loop of information flow, with customer-related information feeding into the NPD process.

The significance of PLM for the product development process is that NPD activities must not take place without reference to the rest of the business. NPD occupies a significant proportion of the planned lead times for getting new products to market, and every step should be monitored and related to a critical path analysis. PLM provides this critical path tool. NPD data need to be accessed during manufacture to ensure conformance to quality standards, accurate labelling and packaging in accordance with customer requirements. Within PLM, visibility of data is integrated within the IT system and is not via a separate software tool. Manufacturing resources are considered within Stage 5 (Resource analysis) of the CPD model (Fig. 8.4) and data that are accessible at the product development stage greatly assist this aspect of the process. Customer-related data will include information relevant to future

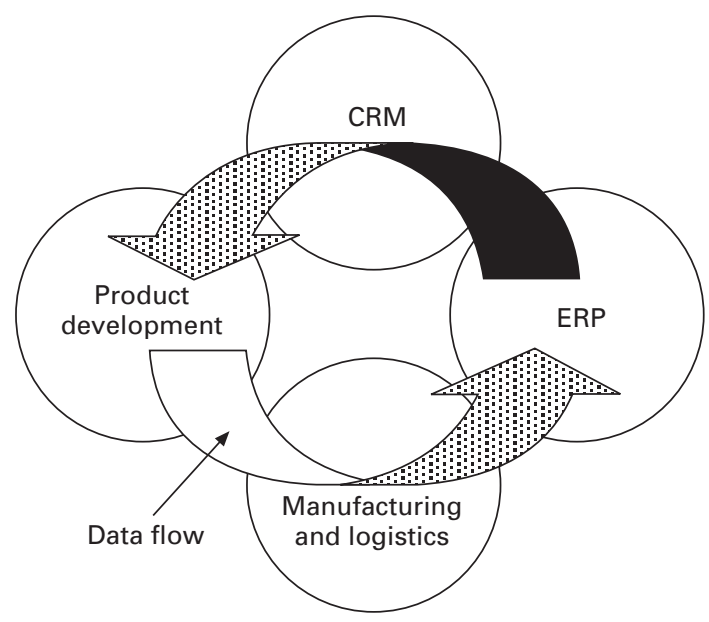

8.6 The PLM concept, showing the context for handling NPD information. 
product development activities, and visibility of this data brings new opportunities to the attention of the NPD team.

As a concluding comment on tools, there are dangers in assuming that investment in tools is the key to developing the business. The main argument of this chapter is that organisational and people issues are actually much more important. Tools are necessary but not sufficient. They are a means to an end. Anecdotal evidence from industry is that when sophisticated software systems are acquired, users often only employ a small part of the functionality - not because this is all they need, but because they have not been trained beyond the basics and because the way the company is organised effectively restricts the full exploitation of the software systems. Organisational change and ongoing staff training should be considered concurrently with investment options.

\subsection{Demand-led new product development}

In the above discussion of the product development process, it was suggested that product developers need to reflect on their own processes and consider whether their timescales are justified and whether they can themselves contribute to time compression. In this section, we consider cases of how shorter timescales can be achieved, and then address NPD for fast fashion.

Colour management issues can contribute significantly to time delays. The term 'lab-dip' is frequently used to refer to a sample that has been dyed to match the standard supplied by the retail customer. These samples are costly to produce, and then they have to be transported by courier to a responsible person (often thousands of miles away) for appraisal. Retailers routinely refer to three, four or even five attempts to get the colour right. The difficulties are often associated with the way the standards are set in the first place, for which the retailer needs to take responsibility. The solutions, via engineered colour standards, are now well documented and are commercially available. A review of the issues is presented by Park (2007). The benefits of engineered colour standards are also documented: the time taken by one retailer to generate master standards has been reduced from 8 weeks to 2 weeks. In addition: 'Typical savings being achieved are a 30-50\% reduction in the number of laboratory submissions from suppliers, with a similar reduction in the time required. It has been claimed by a major retailer that the savings in courier charges alone in 1 year paid for the capital investment in measuring and computer equipment' (Park, 2007, p. 5). This is a good example of where investment in IT will not deliver results without organisational change. The process of specifying colour by the retailer or brand owner needs to change if the technological solutions are to be achieved.

A listing of categories and component activities in the context of quick response $(\mathrm{QR})$ clothing supply in Australia is provided by Perry and Sohal 
(2000). This gives a good indication of what suppliers can do to develop flexible working practices and enhanced responsiveness.

1. The fostering of an ongoing effective working relationship with local supply chain partners, which includes:

- preference for local suppliers (unless not feasible);

- the fostering of win/win supply chain partnerships as opposed to previous power relationships playing off suppliers;

- promotion of supply chain partners' brands;

- the receipt of on-time, in-full deliveries of products.

2. The establishment of procedures to ensure fast product turnaround in the distribution centre.

3. The implementation of technologies and systems for product-related information sharing with supply chain partners, including:

- implementation of point-of-sale scanning;

- the establishment of electronic links with suppliers;

- the provision of weekly sales data to suppliers.

4. The implementation of a comprehensive QR organisation and education programme including, specifically:

- the education of buyers to make buying decisions based on overall costs as opposed to price;

- the education of shop-floor staff regarding individualised service;

- the training of QR officers to work closely with supply chain partners.

The QR strategy has promoted a variety of mechanisms for rapid replenishment of stock items. All of these involve a careful coordination of the whole supply chain, because textiles and commodities cannot be produced at short notice, nor without attention to minimum batch sizes. In a simulation study of responsiveness, Al-Zubaidi and Tyler (2004) found that replenishment times of about 2 weeks are necessary to make a significant difference to the problems of stock-outs and excessive end-of-season inventories. This timescale cannot be achieved by tweaking supply-chain processes: the problem needs a radical process re-engineering exercise.

Warburton and Stratton (2002) discuss the concept of balanced sourcing, which retains sufficient domestic manufacturing to enable short lead times, appropriate for fashion markets, to be achieved. The practice of 'vendormanaged inventory' was explored, particularly in the USA, as a route for domestic manufacturing to compete with offshore suppliers. However, while some successes were reported, it became apparent that the cost advantages to be obtained from sourcing globally were too large to refuse. A recent analysis of business trends (Doyle et al., 2006) emphasises the importance of establishing strong relationships with suppliers, but adds a cautionary note:

[The research] highlights the need to balance the intensive management inherent in a wholly responsive supply chain with the benefits of a two- 
tiered approach to product and supplier management. The research suggests that it is not necessary to pursue a fully responsive supply chain to achieve both agility and product offer dynamism, but instead this can be addressed by identifying only those products and product categories that require rapid and frequent review, replenishment and refreshment. (p. 279)

The challenge many retailers face is that their internal systems require them to base most of their decisions on forecasting. Their timescales for product development are such that all the key decisions are made before the selling season for fashion products. They find it very difficult to make any significant changes to the NPD process model of Fig. 8.2. The consequence is that significant responsiveness cannot be introduced to the supply chain apart from fire-fighting (Tyler et al., 2006). The garment dye route has been developed by domestic suppliers to allow late-stage decisions on coloration, but the UK experience is that diminishing uptake has led to the closure of plants and the remaining capacity cannot handle surges in demand.

Those retailers that are developing a fast fashion offering have modified their NPD processes and have adopted a different internal organisation. Bruce and Daly (2006) identify three elements of a fast fashion strategy. These are:

- 'leagile' approach to supply chain management;

- a blend of long-standing and short-term relationships in the supply chain;

- the effective integration of internal functions and processes.

'Leagile' refers to a combination of lean and agile manufacturing principles and is a term relating to the supply chain. For further discussion of agile supply chains, see Christopher et al., (2004). It is the third of these elements that requires internal change in retail organisations. Bruce and Daly (2006; see p. 339) document three case studies of fashion companies, all of which have sought to achieve time compression.

Common to each case was an integrated internal process whereby sourcing, buying, merchandising and design interfaced effectively to enable rapid decisions about the collection to be made. Technology was used in internal processes and the supply chain to convey the design of the collection, to enable changes to be made quickly and to speed up the design agreement and signing off process. In some cases, sourcing and management of suppliers was an integrated aspect of buying, as in the supermarket case. For the specialist fashion company, the technical team liaised closely with the suppliers, together with the buyers, to ensure that the design was interpreted correctly and to speed up the production time. For all three cases, merchandising was a separate activity, but was involved closely in the whole process of ensuring that product was presented in store quickly. (p. 339) 
Fast fashion has to abandon the two seasons a year planning structure because this always puts a heavy emphasis on forecasting. The planning window has to operate on much shorter timescales. The key processes are:

- focused market research (1 week);

- conceptual design, product development and specification (2 weeks);

- manufacturing (1 week);

- transportation (dependent on location of suppliers and distribution centre).

A review of academic research into fast fashion is given by Barnes and Lea-Greenwood (2007). They identify three models: the Zara model with 'short product life cycles and new product introduction every 3-4 weeks, achieved through fully integrated approach to supply chain'; the street fashion model with products that are 'constantly re-styled from small numbers of basic pre-existing designs. [...] This model makes use of local suppliers [...] and readily available fabrics, enabling a time from concept to delivery of only 2 weeks'; and the Pronto Moda model which is 'closely associated with the quick response model [...] focusing on in-season orders and deliveries to supplement and refresh seasonal stock.' Of these models, the Zara model has attracted the most interest. Zara is the leading brand of the Spanish retail group Inditex SA. The company was formed in 1975 and has seen rapid growth of $30 \%$ annually. It is now a global retailer, reputed to be the third largest. Ferdows et al. (2004) have provided an overview of the company's operational procedures.

Most supply chain models are linear, documenting the forward movement of materials through various processes to become products in the hands of consumers. The models also document the reverse flow of information through the supply chain, triggering activity in accordance with the decisions of the retailer. However, these models do not work for fast fashion. For that, we need a closed-loop systems approach as illustrated in Fig. 8.7 (Ghemawat and Nueno, 2003). Retailing is not at one end of a chain, but is embedded within the process. In particular, retailing is actively involved in assessing

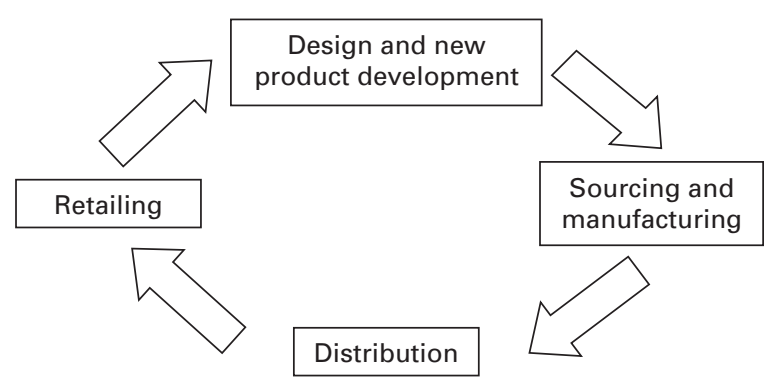

8.7 Systems model for fast fashion retailing. 
consumer demand. This is not just recorded via EPOS data (Electronic Point of Sale systems only document what consumers have purchased) but also involves collating the results of feedback from shoppers about their preferences and their perceptions of fashion trends. Zara have developed simple but effective communication flows from the stores to the hub of the organisation. Twice-weekly call-offs are made against distribution centre stock using a personal digital assistant (PDA). Other trend-related information is fed back to the design centre. This is what turns the concept of demand-led supply into a reality.

The activities in the design centre, in the manufacturing plants and in the distribution centre are all engineered to achieve fast fashion timescales. This requires attention to many practices and technologies that are addressed in manufacturing and supply chain texts. There is, however, merit in drawing attention to the underpinning ideas that give coherence to the various activities. The key characteristics of the Zara approach to fast fashion can be summarised as follows:

- consumer focus to hear the 'voice of the consumer';

- pull processes;

- $\quad$ speed takes priority over cost;

- flow in small batches;

- right-first-time systems;

- simple communication systems supported by IT;

- 'change' is a given;

- indirect promotion with no advertising budget.

These characteristics are all associated with the just-in-time (JIT) philosophy for manufacturing systems. Originating in the Toyota Car Company, the JIT philosophy has spread globally and has changed the way managers think about their manufacturing operations. JIT has provided a radical contrast to traditional approaches and has delivered massive savings in costs, improvements in quality, reduced lead times, enhanced flexibility and enriched employment for the workforce. However, it has made its greatest impact in producer-led supply chains (Gereffi, 1999) because, to be effective, JIT systems need to be integrated with the sales function. JIT has been implemented only in a piecemeal way in buyer-driven supply chains. It has never been able to achieve its full potential because the retail part of the supply chain has not embraced the JIT approach. However, in the case of Zara, it has. Zara can fairly be described as a just-in-time retailer. It is worthy of note that before Zara became involved in retailing, the company was involved in manufacturing. It would appear that the values and practices of manufacturing have not been lost during Zara's transformation into a global retailer. 


\section{8 $\quad$ Future trends}

The clothing industry is dominated by retailers who manage their business activities via buyer-driven supply chains. All retailers seek enhanced flexibility and short lead times for their fashion products. This is deemed essential to reduce risk in a volatile market. In order to assess where the industry is going, it is useful to categorise retailers into two broad categories: those who see their company as the customer, and those who see consumers as customers.

Those retailers who see the company as the customer tend not to see themselves as part of the supply chain. They tend to put the onus for flexibility, short lead times and responsiveness on the supply chain. This, as has been argued here, is a strategy with limitations. Additional problems are identified by Birtwistle et al. (2003). There is a limit to what can be achieved by this route. This is because these retailers have to build their businesses around forecasting, and product decisions made in this way cannot be easily altered or modified. The trend for these retailers is likely to be a constant struggle to deal with market changes, with compromises being made to deliver only part of the desired responses. Where there is lack of trust in the supply chain, protective strategies are employed to safeguard the future of the businesses involved, and these are likely to have negative impacts on flexibility and responsiveness. The retailers at the head of these supply chains will have limited success at managing risk.

The second group of retailers are those who perceive themselves as an integral part of the supply chain. They recognise that the performance of the supply chain is dependent on the way decisions are made by the buyers and by the relationships that exist between the companies within the supply chain. These retailers will adjust their internal systems to respond to the need for decision-making consistent with the critical path. They will modify their internal procedures so that the procedures are tailored to match desired timescales. Examples of these retailers are provided by Bruce and Daly (2006), with this summary:

Common to each case was an integrated internal process whereby sourcing, buying, merchandising and design interfaced effectively to enable rapid decisions about the collection to be made. Technology was used in internal processes and the supply chain to convey the design of the collection, to enable changes to be made quickly and to speed up the design agreement and signing off process. In some cases, sourcing and management of suppliers was an integrated aspect of buying, as in the supermarket case. For the specialist fashion company, the technical team liaised closely with the suppliers, together with the buyers, to ensure that the design was interpreted correctly and to speed up the production time. For all three cases, merchandising was a separate activity, but was involved closely in 
the whole process of ensuring that product was presented in store quickly. (p. 339)

The retailer has a leadership role in clothing supply, and how that role is interpreted and implemented is the crucial factor for future competitiveness.

\subsection{Sources of further information and advice}

Two useful textbooks on responsiveness in clothing supply chains are Abernathy et al. (1999), A Stitch in Time, and Lowson et al. (1999), Quick Response. Two textbooks on the technologies used in clothing manufacture are Cooklin (2006), Introduction to Clothing Manufacture, and Tyler (2008), Carr \& Latham's Technology of Clothing Manufacture.

\subsection{References}

Abernathy, F.H., Dunlop, J.T., Hammond, J.H. and Weil, D. 1999. A Stitch in Time: Lean Retailing and the Transformation of Manufacturing - Lessons from the Apparel and Textile Industry, Oxford University Press, Oxford.

Al-Zubaidi, H. and Tyler, D. 2004. A simulation model of quick response replenishment of seasonal clothing, International Journal of Retail \& Distribution Management, 32(6), 320-7.

Anon. 1996/97. Clothing World, Dec/Jan, 7.

Barnes, L. and Lea-Greenwood, G. 2007. From concept to consumer: the case of fast fashion, 85th Textile Institute World Conference, 1-3 March 2007, Colombo, Sri Lanka, pp. 499-513.

Bhamra, T., Heeley, J. and Tyler, D. 1998. A cross-sectoral approach to new product development. The Design Journal, 1(3), 2-15.

Birtwistle, G., Siddiqui, N. and Fiorito, S.S. 2003. Quick response: perceptions of UK fashion retailers, International Journal of Retail \& Distribution Management, 31(2), $118-28$.

Bruce, M. and Daly, L. 2006. Buyer behaviour for fast fashion, Journal of Fashion Marketing and Management, 10(3), 329-44.

Christopher, M., Lowson, R. and Peck, H. 2004. Creating agile supply chains in the fashion industry, International Journal of Retail \& Distribution Management, 32(8), 367-76.

Cooklin, G. 2006. Introduction to Clothing Manufacture (2nd edition), Blackwell Publishing Ltd, Oxford.

Doyle, S.A., Moore, C.M. and Morgan, L. 2006. Supplier management in fast moving fashion retailing, Journal of Fashion Marketing and Management, 10(3), 272-81.

Ferdows, K., Lewis, M.A. and Machuca, J.A.D. 2004. Rapid-fire fulfillment, Harvard Business Review, 82(11), 104-10.

Forza, C. and Vinelli, A. 1996. An analytical scheme for the change of the apparel design process towards quick response. International Journal of Clothing Science and Technology, 8(4), 28-43.

Gascoigne, B. 1995. PDM: the essential technology for concurrent engineering, World Class Design to Manufacture, 2(1), 38-42. 
Gereffi, G. 1999. International trade and industrial upgrading in the apparel commodity chain, Journal of International Economics, 48(1), 37-70.

Ghemawat, P. and Nueno, J.L. 2003. ZARA: Fast Fashion, Harvard Business School Cases, June 23, 2003.

Hart, S.J. and Baker, M.J. 1994, The multiple convergent processing model of new product development, International Marketing Review, 11(1), 77-92.

Istook, C.L. 2000. Rapid prototyping in the textile and apparel industry: a pilot project, Journal of Textile and Apparel, Technology and Management, 1(1), 1-14.

King, J.A. 2007. Comparative analysis of the use of colour forecasting information within UK high street retail groups, 85th Textile Institute World Conference, 1-3 March 2007, Colombo, Sri Lanka, pp. 619-27.

Lowson, B., King, R. and Hunter, A. 1999. Quick Response. Managing the Supply Chain to Meet Consumer Demand, John Wiley \& Sons, Ltd, Chichester, UK.

Park, J. 2007. Engineered textile colour standards, Coloration Technology 123(1), 1-7.

Perry, M. and Sohal, A.S. 2000. Quick response practices and technologies in developing supply chains. A case study, International Journal of Physical Distribution \& Logistics Management, 30(7/8), 627-39.

Popp, A. 2000. Swamped in information but starved of data: information and intermediaries in clothing supply chains, Supply Chain Management, 5(3), 151-61.

Saren, M. 1984. A classification of review models of the intra-firm innovation process, $R \& D$ Management, 14(1), 11-24.

Tyler, D.J. 2008. Carr \& Latham's Technology of Clothing Manufacture (4th edition), Blackwell Publishing Ltd, Oxford.

Tyler, D., Heeley, J. and Bhamra, T. 2006, Supply chain influences on new product development in fashion clothing, Journal of Fashion Marketing and Management, 10(3), 316-28.

Warburton, R.D.H. and Stratton, R. 2002. Questioning the relentless shift to offshore manufacturing, Supply Chain Management, 7(2), 101-108.

Watson, K. 1997. Benefits of supply chain partnerships. In Putting Energy into the Supply Chain, Textile Conference, 19 March 1997, Birmingham, UK. 